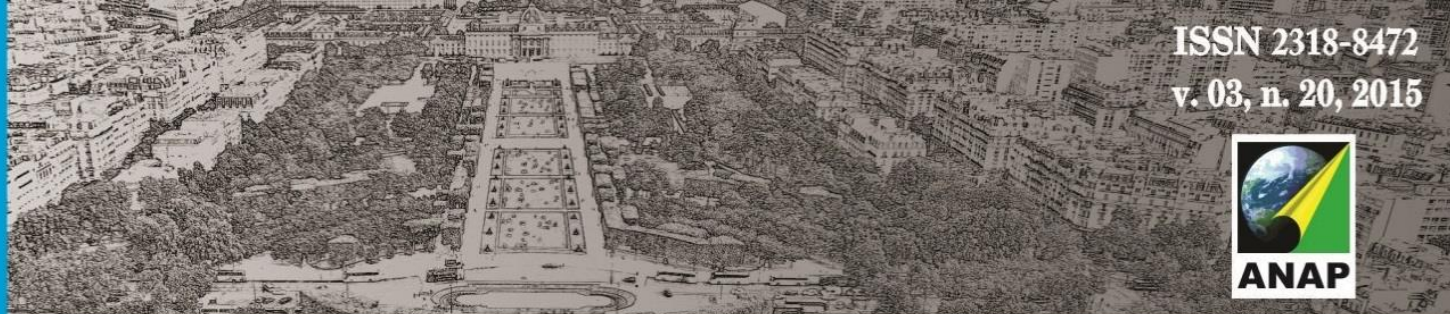

Revista Nacional de

Gerenciamento de Cidades

\title{
POLÍTICA NACIONAL DE RESÍDUOS SÓLIDOS E OS CATADORES DE MATERIAIS RECICLÁVEIS: ESTUDO DE CASO DE COOPERATIVAS NOS MUNICÍPIOS DO ESTADO DO RIO DE JANEIRO
}

\author{
Tatiane dos Santos Alencar ${ }^{1}$ \\ João Pedro Maciente Rocha ${ }^{2}$
}

Rebeca Valentim da Silva ${ }^{3}$

\begin{abstract}
RESUMO
Os resíduos sólidos representam uma das questões socioambientais mais sérias atualmente. No Brasil, um dos maiores problemas relacionados à temática consistiam nos lixões, forma de disposição final inapropriada adotada pela maioria dos municípios ao longo dos anos. Em 2010, com a promulgação da Lei 12.305, que estabelece a Política Nacional de Resíduos Sólidos (PNRS), buscouse mitigar as ações que traziam malefícios para o meio ambiente e sociedade. Esta mudança além de tratar das questões ambientais, também garante o reconhecimento do resíduo reciclável como gerador de trabalho e renda e promotor da cidadania. O presente trabalho tem como objetivo avaliar a implementação da PNRS e suas consequências a partir do estudo de caso dos catadores de materiais recicláveis atualmente organizados em cooperativas, distribuídos em alguns municípios do estado do Rio de Janeiro. Baseado em pesquisas bibliográficas e visitas de campo, abordar-se-á os efeitos da desativação dos lixões e aterros controlados e suas implicações para os catadores dessas cooperativas. Através do trabalho desenvolvido junto a Incubadora Tecnológica de Cooperativas Populares da Universidade Federal do Rio de Janeiro - ITCP COPPE UFRJ com os empreendimentos, é possível identificar características específicas deste grupo marginalizado, bem como oportunidades e desafios existentes para real inclusão social dos catadores. Em termos quantitativos, foram capacitados 400 catadores nos municípios e 20 empreendimentos recebem assistência técnica. Sendo assim, através do cooperativismo popular, é possível não somente garantir a mitigação dos problemas ambientais, como também empoderar tal grupo social e promover geração de trabalho e renda, assegurados na referida lei.
\end{abstract}

PALAVRAS-CHAVE: Política Nacional de Resíduos Sólidos. Catadores de Materiais Recicláveis. Geração de Trabalho e Renda.

\footnotetext{
${ }^{1}$ Mestranda em Engenharia Ambiental pela Universidade do Estado do Rio de Janeiro; técnica da Incubadora Tecnológica de Cooperativas Populares ITCP COPPE UFRJ tatiane.santos.alencar@gmail.com

${ }_{2}$ Mestrando em Engenharia Urbana pela Universidade Federal do Rio de Janeiro; técnico da Incubadora Tecnológica de Cooperativas Populares ITCP COPPE UFRJ jpmacienterocha@gmail.com

3 Pós graduanda em Engenharia Urbana pela Universidade Federal do Rio de Janeiro; bolsista da Incubadora Tecnológica de Cooperativas Populares ITCP COPPE UFRJ rebeca.valent@gmail.com;
} 


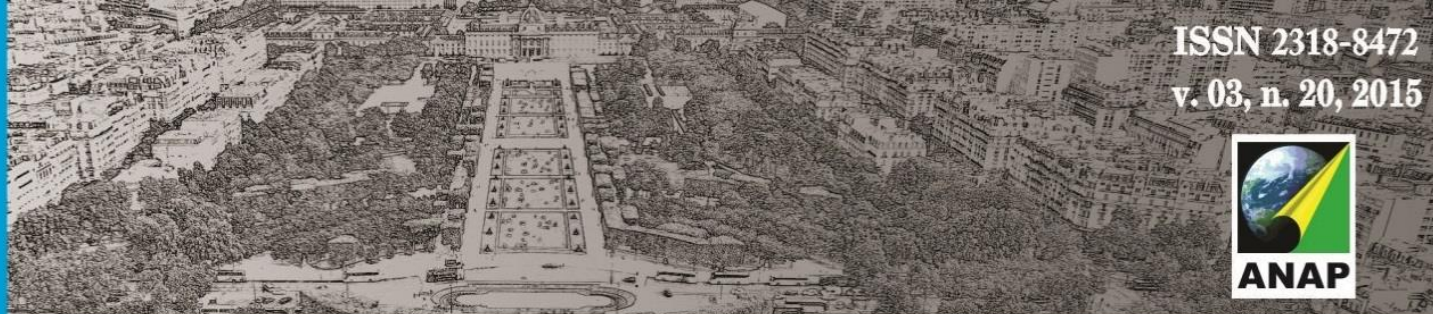

Revista Nacional de

Gerenciamento de Cidades

\title{
NATIONAL POLICY OF SOLID WASTE AND RECYCLABLE MATERIAL COLLECTORS: COOPERATIVE CASE STUDY IN THE CITIES OF STATE OF RIO DE JANEIRO
}

\begin{abstract}
Solid waste represent one of the environmental issues currently more serious. In Brazil, one of the largest theme-related problems consisted in landfills form of inappropriate disposal adopted by most municipalities over the years. In 2010, with the enactment of Law 12,305, establishing the National Policy on Solid Waste (PNRS), we sought to mitigate the actions that brought harm to the environment and society. This change in addition to dealing with environmental issues also ensures the recognition of recyclable waste as job generator and income of citizenship promoter. This study aims to evaluate the implementation of PNRS and its consequences from the case study of waste pickers currently organized into cooperatives, distributed in some municipalities of the state of Rio de Janeiro. Based on literature searches and field visits, will address them-effects of disabling dumps and controlled landfills and its implications for the collectors of these cooperatives. Through the work with the Technological Incubator of Popular Cooperatives of the Federal University of Rio de Janeiro - ITCP COPPE UFRJ with the projects you can identify specific characteristics of this marginalized group, as well as existing opportunities and challenges for real social inclusion of waste pickers. In quantitative terms, they were trained 400 collectors in the municipalities and 20 projects receive technical assistance. Thus, through the popular cooperative, it can not only ensure the mitigation of environmental problems, but also empower such a social group and promote generation of jobs and income, guaranteed by that law.
\end{abstract}

KEYWORDS: National Solid Waste Policy. Recyclable materials. Generation of Work and Income.

\section{POLÍTICA NACIONAL DE RESIDUOS SÓLIDOS Y COLECTORES MATERIAL RECICLABLE: ESTUDIO DE CASO DE COOPERACIÓN EN LAS CIUDADES DE ESTADO DE RIO DE JANEIRO}

\begin{abstract}
RESUMEN
Los residuos sólidos representan uno de los problemas ambientales más graves actualmente. En Brasil, uno de los mayores problemas relacionados con el tema consistía en vertederos forma de eliminación inadecuada adoptada por la mayoría de los municipios en los últimos años. En 2010, con la promulgación de la Ley 12305, que establece la Política Nacional de Residuos Sólidos (PNRS), hemos tratado de mitigar las acciones que provocaron daños al medio ambiente y la sociedad. Este cambio, además de tratar las cuestiones ambientales, también garantiza el reconocimiento de los residuos reciclables como generador de empleo y de ingresos del promotor de la ciudadanía. Este estudio tiene como objetivo evaluar la aplicación de PNRS y sus consecuencias desde el estudio de caso de los recicladores organizados actualmente en cooperativas, distribuido en algunos municipios del estado de Río de Janeiro. En base a búsquedas bibliográficas y visitas de campo, abordará les efectos de la desactivación de los vertederos y rellenos sanitarios controlados y sus implicaciones para los coleccionistas de estas cooperativas. A través del trabajo con la Incubadora Tecnológica de Cooperativas Populares de la Universidad Federal de Río de Janeiro - UFRJ PICT COPPE con los proyectos que usted puede identificar las características específicas de este grupo marginado, así como las oportunidades existentes y los desafíos para la inclusión social real de los recicladores. En términos cuantitativos, fueron capacitados 400 colectores en los municipios y 20 proyectos reciben asistencia técnica. De este modo, a través de la cooperativa popular, que puede no sólo garantizar la
\end{abstract}




\section{Revista Nacional de}

Gerenciamento de Cidades

mitigación de los problemas ambientales, sino también capacitar a un grupo tan social y promover la generación de empleo y renta, garantizadas por la misma ley.

PALABRAS CLAVE: Política Nacional de Residuos Sólidos. Los materiales reciclables. Generación de Trabajo y Renta.

\section{INTRODUÇÃO}

Os resíduos sólidos representam uma das questões socioambientais mais sérias atualmente. Isso se dá pelo fato de que, independentemente do local ou condição de vida da população, encontram-se em relação direta com os indivíduos, que o geram. (OKADA, 2011). A fim de evitar uma análise demasiadamente superficial de tão complexo assunto, é necessária uma abordagem multidisciplinar, onde diversos aspectos devem ser considerados.

No Brasil, há uma preocupação latente com relação à quantidade de resíduos sólidos gerados e a melhor forma de garantir um gerenciamento, tratamento, destinação e disposição final adequados. Um dos maiores problemas relacionados a esse assunto, consistiam nos lixões, forma de disposição final inapropriada adotada pela grande maioria dos municípios.

Com a presença de materiais passíveis de reaproveitamento e com as desigualdades sociais existentes no Brasil, os lixões tornaram-se, ao longo dos anos, um dos lugares onde pessoas de baixa renda buscavam seu sustento, através da separação de materiais que podem ser reciclados. Neles, entretanto, havia riscos consideráveis não só para o meio ambiente, como também aos catadores que ali trabalhavam, sendo um espaço propício para reprodução de vetores e outros elementos patológicos, que poderiam colocar em risco sua saúde física. (MONTEIRO et al, 2001).

Tendo em vista esse cenário, em setembro de 2007 foi encaminhada ao Congresso Nacional pelo Executivo, uma proposta de Política Nacional de Resíduos Sólidos, PNRS, com o projeto de lei 1991/07. Para isto, houve a participação de 
Revista Nacional de

Gerenciamento de Cidades

diversos setores do governo e da sociedade civil. Três anos depois foi decretada a lei 12.305/2010, que criou a PNRS, tendo como objetivo estabelecer uma nova estrutura, logística e uma postura comportamental diferenciada.

No âmbito comportamental, frisa-se para uma atenção em todo o processo, buscando minimizar a sua geração, se atentar para as novas tecnologias para melhoria da destinação final e por fim, reduzir a quantidade de materiais a serem encaminhados para a disposição final. Ainda com relação a este último aspecto, há o estabelecimento do fim dos lixões e demais formas de disposição final inadequadas, prevista em seu artigo 54.

Para promover essas ações, são elencados na lei 12.305/2012, em seu artigo 9․, cinco elementos básicos e fundamentais para sua implementação: hierarquia na gestão, responsabilidade compartilhada, logística reversa, incentivos econômicos e planos de gerenciamento. (OKADA, 2011).

Ressalta-se que grande parte dos catadores estava nos lixões e aterros controlados espalhados pelo Brasil, e com a proibição do exercício de atividades nesses locais, previsto no artigo 48으, inciso II por determinação da PNRS, há a necessidade de integrá-los na cadeia de reciclagem, promovendo a inclusão social através da cidadania, assim como a geração de trabalho e renda.

O benefício previsto à sociedade através da implementação das ações previstas na PNRS é o incentivo direto ao desenvolvimento urbano com investimentos em educação ambiental, geração de emprego e renda e oportunidades de investimentos para empresários, além de poder promover o desenvolvimento social com incentivos à qualificação e incorporação ao mercado de trabalho de catadores de materiais recicláveis e reutilizáveis. (AMARAL, 2013).

Se na teoria havia a previsão de melhores condições e fortalecimento de condições de trabalho para os catadores, na prática, eles perderam significativamente sua fonte de renda. Somado a isso, de acordo com os dados do Plano Nacional de Resíduos Sólidos, realizado pelo Ministério do Meio Ambiente no ano de 2012, no país, há entre 400 e 600 mil catadores. Entre 40 e 60 mil catadores 


\section{Revista Nacional de}

Gerenciamento de Cidades

participam de alguma organização coletiva, correspondendo a apenas $10 \%$ de sua população total, e cerca de $60 \%$ das organizações coletivas e dos catadores estão nos níveis mais baixos de eficiência. Vê-se então a necessidade de ações voltadas especificamente para este grupo a fim de que haja a inclusão social, geração de trabalho e renda e aumento da eficiência produtiva.

Com o objetivo de contribuir para maior expressividade de inserção deste grupo, diversas instituições atuam visando fortalecer a profissionalização dos catadores. A fim de inseri-los no mercado formal de trabalho, busca-se garantir que o previsto no papel possa ser de fato executado, beneficiando aqueles que possuem este direito.

A Incubadora Tecnológica de Cooperativas Populares, da Universidade Federal do Rio de Janeiro, ITCP COPPE UFRJ, consiste em uma dessas instituições. Criada em 1995, a ITCP através do cooperativismo popular ${ }^{4}$ visa promover a geração de trabalho e renda de grupos marginalizados da sociedade. $\mathrm{O}$ trabalho voltado especificamente para os catadores de materiais recicláveis será descrito posteriormente.

\section{OBJETIVOS}

Este trabalho tem como objetivo geral avaliar os efeitos de aplicação da política pública implementada através da Política Nacional de Resíduos Sólidos, sobretudo do estabelecido em seu artigo 54, que obriga a desativação dos lixões e sua substituição para uma disposição final ambientalmente adequada, assim como suas consequências diretas para os catadores de materiais recicláveis, organizados em cooperativas em alguns municípios do estado do Rio de Janeiro.

\footnotetext{
${ }^{4}$ Consiste em "uma releitura da ideologia cooperativista, criada no século XIX, que se diferencia pela situação de exclusão vivenciada por seus associados e pela predominância da participação e democracia na gestão, menos voltada para o lucro e mais para o bem comum". (GUIMARÃES, 2000).
} 
Revista Nacional de

Gerenciamento de Cidades

\section{METODOLOGIA / MÉTODO DE ANÁLISE}

A metodologia adotada para realização deste estudo de caso consistiu em pesquisas bibliográficas e documentais, além de observações e conversas mantidas nas visitas de campo realizadas entre os meses de agosto de 2014 e abril de 2015 . Tais atividades ocorreram em virtude da realização do projeto intitulado "Economia Solidária ${ }^{5}$ e redes de cooperação: estratégias para inclusão produtiva e consolidação da sustentabilidade dos empreendimentos de catadores", promovido pela Incubadora Tecnológica de Cooperativas Populares, em parceria com o Ministério do Trabalho e Emprego, MTE, e Secretaria Nacional de Economia Solidária, SENAES. Através dele, a partir das atividades da equipe de assessoria técnica, foi possível ver mais de perto os desafios dos catadores, bem como do poder público para implementação dos dispositivos estabelecidos na lei.

Para este estudo, recorreu-se a uma abordagem qualitativa, descritiva e exploratória. Justifica-se como abordagem exploratória levando em consideração a magnitude do fenômeno da desativação dos lixões e descrição das consequências diretas para os catadores de materiais recicláveis, e que diante da insuficiência de estudos que abordem esta questão, apresenta também sua relevância.

\section{METODOLOGIA DA ITCP}

A Incubadora Tecnológica de Cooperativas Populares, ITCP COPPE UFRJ foi criada em 1995 na Universidade Federal do Rio de Janeiro, a partir da demanda

\footnotetext{
5 De acordo com o site institucional do Ministério do Trabalho e Emprego, compreende "uma diversidade de práticas econômicas e sociais que realizam atividades de produção de bens, prestação de serviços, finanças solidárias, trocas, comércio justo e consumo solidário [...] organizadas sob a forma de autogestão". Apresenta-se também como uma inovadora alternativa para geração de trabalho e renda, sendo também uma resposta para a inclusão social.
} 


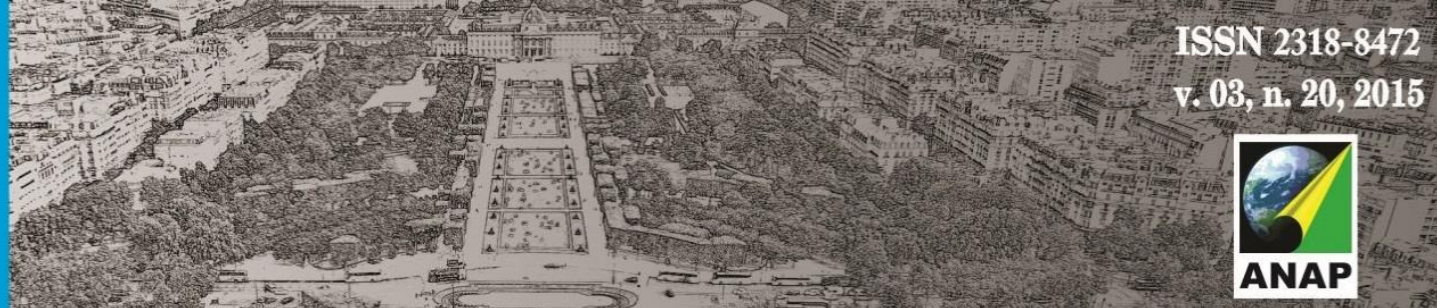

Revista Nacional de

Gerenciamento de Cidades

observada por um grupo de estudiosos e profissionais da COPPE, que desejaram transferir a metodologia da incubadora de empresas para os Empreendimentos Econômicos Solidários ${ }^{6}$ (EES) brasileiros, numa forma de atingir grupos marginalizados da sociedade. Sendo assim, seu objetivo central é o de inseri-los no mercado formal de trabalho, a partir da transferência de conhecimento da universidade para estes grupos, carentes de conhecimento para crescimento profissional.

A ITCP utiliza em sua metodologia a pedagogia da alternância ${ }^{7}$, que possibilita a apreensão dos conhecimentos teóricos, oriundos da universidade, e o prático, que os trabalhadores marginalizados possuem pela vivência de suas atividades no dia a dia. Sendo assim, a ITCP criou uma metodologia intitulada INCUBCOOP, baseada no "aprender fazendo". Através da educação popular, a metodologia prevê o foco em cinco pontos: Organização do Grupo; mobilização e identificação e fortalecimento de lideranças; formação técnica; organização do trabalho; comercialização dos produtos e serviços.

Há dentro dessa metodologia a divisão em três vertentes: social, econômica e tecnológica. $\mathrm{Na}$ vertente social, aspectos básicos da cidadania e as relações do empreendimento com a sociedade são trabalhados. Na vertente econômica, abordam-se questões como a sustentabilidade do empreendimento, possíveis fontes de financiamento para suas atividades, dentre outros. Na vertente tecnológica trabalha-se com os instrumentos disponíveis e passíveis de apreensão para melhor organização do grupo e consequentemente, melhoria de seu trabalho e produção.

A metodologia é aplicada aos grupos em duas fases: a pré-incubação e a incubação. Na primeira, são trabalhadas as questões básicas de cidadania dos

\footnotetext{
${ }^{6}$ De acordo com o site do Ministério de Trabalho e Emprego (2015), os EES são organizações coletivas e suprafamiliares, incluindo as cooperativas, cujos participantes consistem em trabalhadores dos meios urbano e rural, que exercem em suas atividades a autogestão. Esses grupos devem ser permanentes, podendo já estar em operação ou não, dispondo ou não de registro legal, e que realizem atividades econômicas voltadas para a produção de bens, prestação de serviços, de comercialização, de fundo de crédito e de consumo solidário.

7 Consiste em uma metodologia de organização de ensino que conjuga diferentes experiências formativas distribuídas ao longo de tempos e espaços distintos, tendo como finalidade uma formação profissional. (Teixeira et al, 2008)
} 

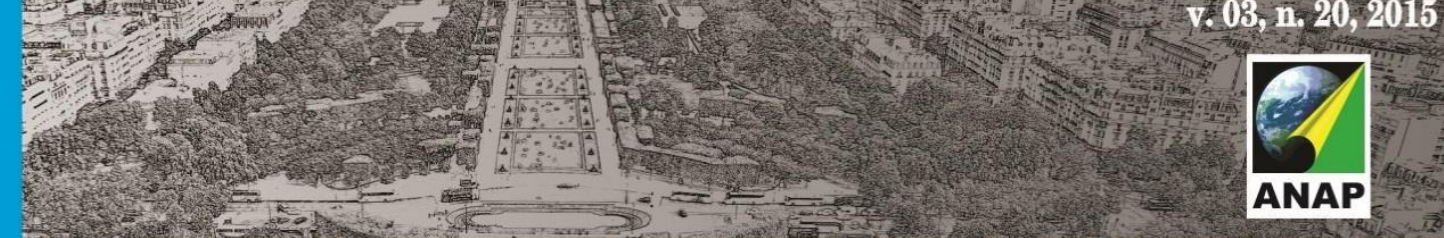

Revista Nacional de

Gerenciamento de Cidades

cooperados, bem como é elaborado o projeto da cooperativa, que permite uma compreensão geral do projeto a ser perseguido. Na fase de incubação, a incubadora busca desenvolver cursos, projetos, articulações e treinamentos junto aos cooperados e aos parceiros alcançados (como por exemplo, prefeituras, comunidades do entorno, agentes privados, ONGs, escolas) para dar sustentabilidade à cooperativa.

\section{METODOLOGIA DO PROJETO}

Desenvolvido pela ITCP COPPE UFRJ a partir do edital de chamada pública de Parceria SENAES/ MTE №004/2011, o projeto intitulado "Economia Solidária e redes de cooperação: estratégias para inclusão produtiva e consolidação da sustentabilidade dos empreendimentos de catadores" vem sendo executado desde janeiro de 2012. Atualmente, o projeto encontra-se em andamento e tem previsão para o fim de suas atividades em novembro de 2015.

Diante de um novo cenário com a criação da Política Nacional de Resíduos Sólidos e considerando o trabalho dos catadores de materiais recicláveis, houve o estímulo para criação de políticas públicas que busquem transformar a realidade existente; a atuação da ITCP visa fortalecer Empreendimentos Econômicos Solidários da cadeia de reciclagem, com vistas a retirar o maior número possível de pessoas da condição de extrema pobreza.

O Sistema Nacional de Informações de Economia Solidária (SIES), criado em 2004, é um instrumento utilizado pela SENAES para identificar e registrar informações dos EES e das entidades que apoiam e fomentam as políticas públicas de Economia Solidária. De acordo com o SIES, em seu Boletim Informativo no ano de 2013, na região sudeste, campo mais atuante da ITCP COPPE UFRJ, dentre as formas de organização possíveis, a de cooperativas corresponde a cerca de $10 \%$ dos EES e a porcentagem de grupos informais chega a 48,5\%. Em se tratando da área de materiais recicláveis, para maior inserção de seus trabalhadores, vê-se a 


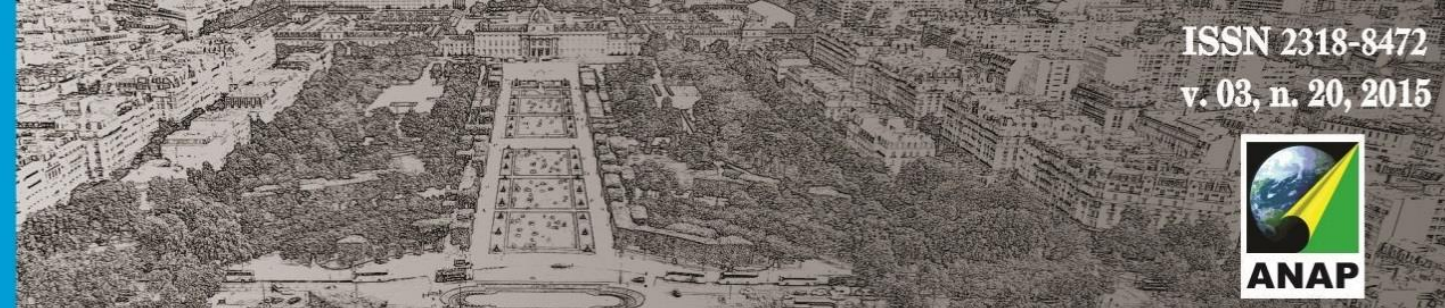

Revista Nacional de

Gerenciamento de Cidades

O projeto cobre uma área carente da Região Metropolitana, que sofre com o clássico desenho político, econômico e social das metrópoles brasileiras: as desigualdades, que se acentuam quando há o afastamento do centro econômico e político e se dirige às periferias. Os municípios periféricos recebem os resíduos da cidade, e estes não são poucos. De acordo com os dados do Plano Estadual de Resíduos Sólidos de 2013, a Região Metropolitana é a que mais produz resíduo por habitante ao dia no estado do Rio de Janeiro, com índice de geração per capita de $1,19 \mathrm{~kg} / \mathrm{hab} / \mathrm{dia}$, valor este acima da média estadual, correspondente a 1,10 $\mathrm{kg} / \mathrm{hab} / \mathrm{dia}$.

A péssima distribuição de renda, associada a um cenário de investimento social baixo, contribui para criação e perpetuação de uma população vulnerável e contabilizada na condição de pobreza extrema, justificando assim, a escolha do local para implementação do projeto.

Além destes municípios, no decorrer do projeto viu-se a necessidade de ampliar o campo de atuação. $\mathrm{Na}$ medida em que era feito $\mathrm{O}$ trabalho de sensibilização com os catadores, as prefeituras dos municípios ao redor e os próprios catadores solicitaram apoio à ITCP para capacitação e suporte na criação de cooperativas em outros locais. O projeto se espraiou então para Duque de Caxias, Nova Iguaçu, Mesquita, Itaguaí, Japeri, Mangaratiba, Volta Redonda e Barra Mansa.

O projeto foi estruturado em três etapas, divididas em objetivos definidos e verificáveis através de sete metas, a saber: Capacitação da equipe; Articulação Institucional; Capacitação e incubação dos grupos, Assistências Técnicas aos empreendimentos formalizados e em atuação; Assistências Técnicas aos grupos recém-formados; Oficinas para resgate de autoestima; e Oficinas de Inclusão, Meio Ambiente e Sustentabilidade. Elas guardam relações recíprocas de complementaridade, sendo, em muitos casos, organizadas e realizadas concomitantemente. 


\section{Revista Nacional de}

Gerenciamento de Cidades

\section{ETAPAS DO PROJETO}

A primeira etapa envolveu seleção e contratação da equipe, ocorrida no início de 2012 e sua posterior capacitação, realizada por especialistas de comprovada atuação em cada um dos temas contidos no plano de trabalho. Concomitantemente ao processo de capacitação, os articuladores institucionais iniciaram o processo de sensibilização, registro dos catadores de rua e de lixão, organização dos grupos e seleção de cooperativas em atuação.

Dentre os assuntos trabalhados nos oito módulos da capacitação, citam-se o histórico dos catadores de materiais recicláveis; a Política Nacional de Resíduos Sólidos, formalização e Legalização dos empreendimentos; cadeia de reciclagem e sustentabilidade, gestão e logística reversa dentre outros. Essa etapa da capacitação visa dar conhecimentos e instrumentos para que o catador, enquanto pessoa física, esteja inserido nos assuntos pertinentes a sua área de atuação, bem como tenha condições para posteriormente responder pela cooperativa, enquanto pessoa jurídica.

$\mathrm{Na}$ segunda etapa tem início à aplicação de oficinas para resgate de autoestima através da cultura e do trabalho cooperativo, que está intimamente relacionada às atividades de articulação institucional, formação dos grupos e seleção das cooperativas.

A estratégia é garantir que, aliada à formação técnica dos catadores e à transferência de tecnologia, a situação global na qual se insere a atividade de catação e reciclagem, seja avaliada. Dentre os temas abordados nesta etapa, temse a formação aplicada às famílias, logística de mobilização, bem como oficinas de Políticas Públicas de Educação, Saúde e Recursos Sociais.

A terceira etapa engloba as metas referentes à assistência técnica para empreendimentos em atuação e para os novos grupos formados pelo projeto e oficinas variadas. Elas visam garantir um aprimoramento da qualidade técnica das 


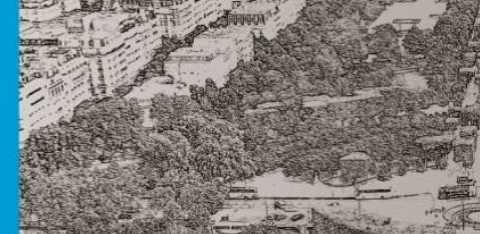

\section{Revista Nacional de}

Gerenciamento de Cidades

cooperativas e ampliar os postos de trabalho, com aumento da capacidade de trabalho e produção dos grupos.

Nesta etapa, visa-se garantir a ampliação da formação e capacitação de indivíduos e grupos para lidar com os desafios cada vez mais complexos da cadeia produtiva de resíduos recicláveis. A estratégia é ampliar as habilidades e competências dos indivíduos, para criar grupos mais densos e conscientes.

A última etapa do projeto desdobra uma série de questões contemporâneas, ligadas à complexificação da cadeia produtiva e dos desafios que as cooperativas de catadores enfrentam para se posicionar no mercado de forma sustentável. É o amadurecimento do processo que $\mathrm{o}$ projeto propõe executar, levando em consideração demandas que vão além da capacitação pontual e respondendo às exigências atuais de formação de grupos capazes de atingir a sustentabilidade e proteger o meio ambiente do descarte inadequado dos resíduos.

\section{RESULTADOS}

Durante a atuação, os técnicos da ITCP devem levar em consideração o fato de que há mudanças significativas na transição de uma atividade individual para coletiva. É necessário então, um período de formação para os catadores, sem que essa ação interfira na dinâmica da atividade principal deles e que traz sua fonte de renda, a catação. Por meio de um diálogo, e de comum acordo, foi estabelecido encontros semanais para realização das atividades do projeto com os grupos, no período da manhã ou da tarde.

Ao decorrer das ações, os integrantes puderam ter as oficinas, previstas com a capacitação, bem como o início do trabalho da assistência técnica. Em termos quantitativos, foram mais de 600 catadores de materiais recicláveis sensibilizados, 400 capacitados e atualmente, 20 grupos recebem assistência técnica. Destes, muitos são oriundos da atividade de catação nos antigos lixões, hoje desativados. 


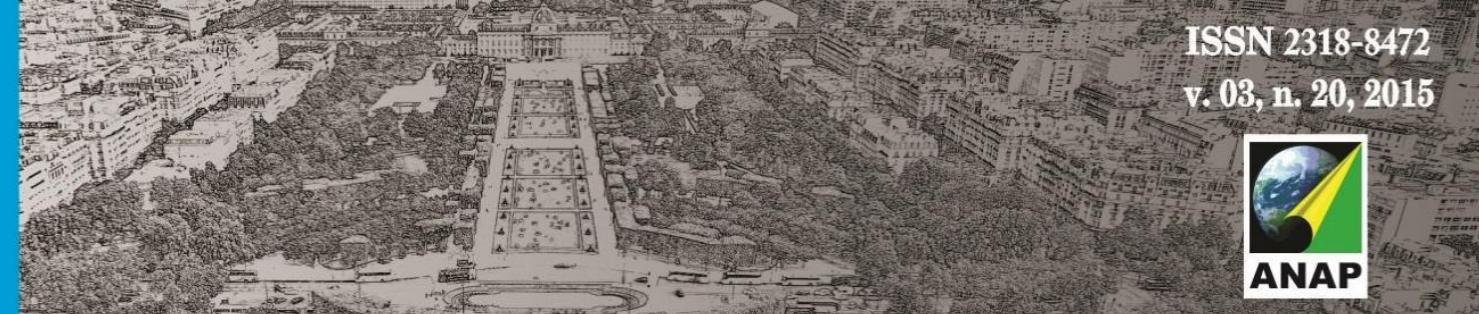

\section{Revista Nacional de}

Gerenciamento de Cidades

Figura 2: Atividades realizadas pela equipe junto aos catadores

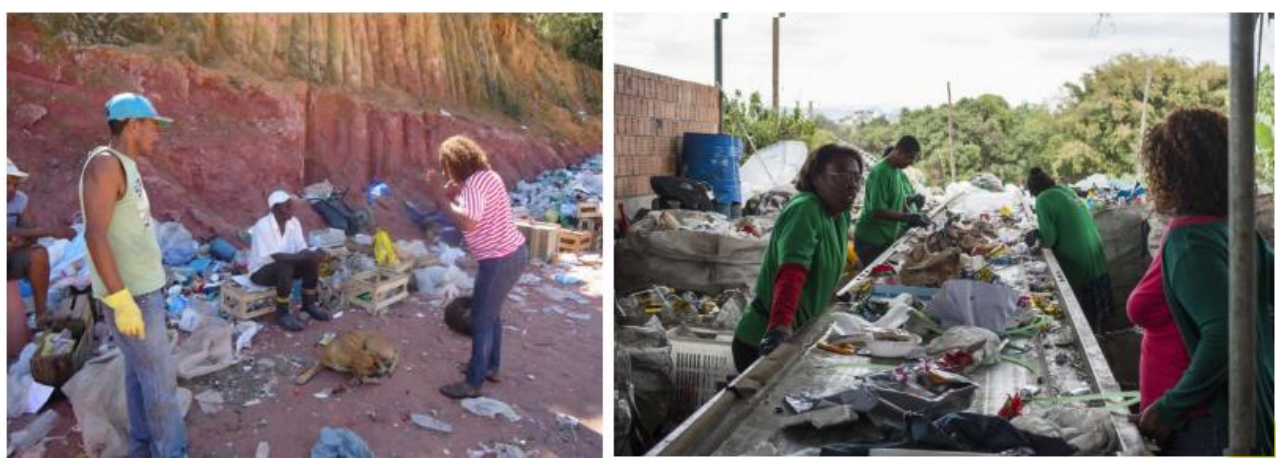

Fonte: Banco de Imagens ITCP, 2013.

Foi a partir da assistência técnica que as percepções com os grupos e com a situação que os envolviam puderam ser apreendidas para esta pesquisa. Ao longo dos relatos e deparando com a situação atual, houve o questionamento do que poderia ser feito, e quais são as oportunidades e desafios para os empreendimentos. A partir de então, traça-se uma análise do que foi visto em campo.

Observa-se que há inicialmente algumas dificuldades relacionadas às questões culturais, adquiridas e desenvolvidas ao longo de suas atividades de catação, que precisam ser consideradas durante a execução do projeto. Os catadores, ao saírem de suas atividades individuais e quando inseridos nas cooperativas, tem uma modificação nas dimensões temporais, saindo da lógica diária e indo para semanal, quinzenal ou mensal com relação ao repasse financeiro proveniente da venda dos materiais.

Outro ponto relevante no tocante às dificuldades dos catadores diz respeito ao fato de anteriormente se pensar de maneira individual, onde o mesmo podia estabelecer suas atividades, e caso quisesse, não possuir uma rotina. Ao iniciar seu trabalho na cooperativa, a fim de ter melhor gestão do empreendimento, torna-se necessária certa adaptação ao novo contexto, com o objetivo central de pensar no 'melhor para o grupo'. 

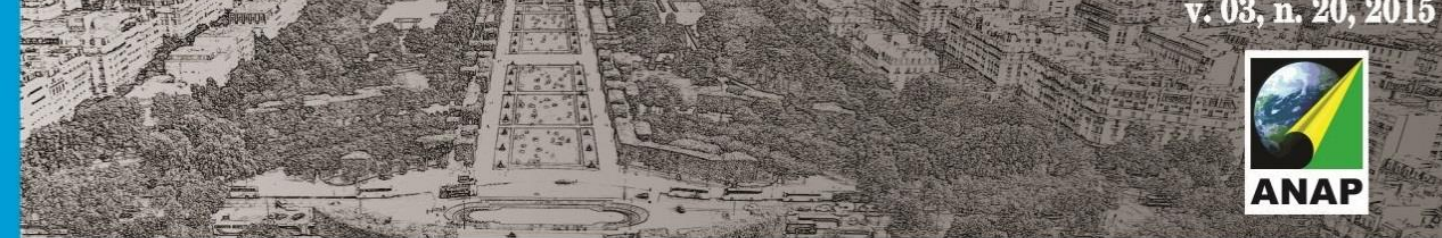

Revista Nacional de

Gerenciamento de Cidades

Há que se observar essa realidade, os valores, e as conjunturas que os catadores possuem, respeitando seu tempo e seu espaço, a fim de que possam chegar à percepção do novo cenário e contexto em que estão inseridos, de forma a gerar sua emancipação política e sustentabilidade do empreendimento.

Essa realidade gera formas de resistência social, resultantes da conflitividade e reivindicação, incluindo-se também questões de herança cultural. Observa-se que diante da marginalização deste grupo, é necessário ter um efeito de mobilização de ação dos próprios catadores, que veem a necessidade de organização política para ter voz e vez. Embora aparentemente possa não haver um resultado efetivo a curto prazo, ao longo dos anos, pode-se ter uma alteração política, uma mudança cultural. Isso se dá pela existência de grupos mais coesos e integrados, bem como pela representatividade institucional dos catadores.

\section{DESAFIOS PARA OS EMPREENDIMENTOS}

Dadas às condições de desigualdade social existentes, as dificuldades em absorver a mudança em seu tempo para receber a remuneração, não mais em uma lógica diária, mas semanal, quinzenal ou mensal, bem como a organização coletiva e não mais individual, pode haver certas dificuldades de inicialmente o catador se adaptar. A situação pode ser agravada quando há a venda de poucos materiais recicláveis, trazendo um retorno financeiro menor do que esperado.

Com isso, verifica-se que muitos catadores em busca de algo que thes traga maior fonte de renda, saem das cooperativas, gerando grande rotatividade. Muitas vezes, esses catadores acabam voltando para as cooperativas, dada sua baixa qualificação técnica e nível de escolaridade para exercer outra atividade.

Tal ação acaba gerando para a cooperativa certa instabilidade quanto ao número de cooperados. Outra dificuldade diz respeito ao fato de que a maioria das cooperativas não possui um espaço com capacidade de armazenamento de grandes volumes. Isso gera a necessidade de venda de seus resíduos para intermediários, 


\section{Revista Nacional de}

Gerenciamento de Cidades

os atravessadores. Teoricamente, estes consistem em uma espécie de facilitador da comunicação entre a empresa e a cooperativa.

Na prática, é um agente de comunicação direta com a cooperativa que paga valor inferior pelos materiais vendidos. Estes atores tem a capacidade de comprar e armazenar grandes quantidades de materiais, devido ao fato de terem a infraestrutura necessária para trabalhar com o resíduo, agregando valor, e posteriormente vendendo o mesmo para os grandes compradores e indústrias consumidoras.

Uma das dificuldades encontradas consiste na sustentabilidade financeira. Agravada pela revenda de materiais recicláveis aos atravessadores, que pagam valor inferior aos materiais, às cooperativas populares não possuem condições de contribuir com valores maiores para contribuir para o fundo de reserva do empreendimento, quando realizam essa contribuição.

Ainda sobre os desafios dos grupos do presente estudo, identifica-se a ausência de equipamentos que poderiam agregar valor aos seus resíduos, como prensas para realizar o enfardamento dos materiais, bem como balanças ou mesas de triagem. A razão principal consiste na ausência de recursos financeiros para adquirir estes bens.

\section{ASPECTOS POSITIVOS PARA OS EMPREENDIMENTOS}

Durante as atividades do projeto, algumas ações foram desenvolvidas com o objetivo de fortalecer o grupo e minimizar com os problemas e desafios apontados no tópico anterior. Uma das ações realizadas junto ao grupo consistiu no fortalecimento e articulação da rede, segunda instância política de articulação dos catadores, iniciada nos municípios de Duque de Caxias e Mesquita, por exemplo, contando com seis e quatro grupos, respectivamente. Tal ação é capaz de gerar integração entre os empreendimentos, bem como aumentar suas chances de representatividade política para lutarem por seus objetivos. 
A criação da rede também permitiria, no âmbito econômico, a concentração da oferta de materiais recicláveis, permitindo uma participação importante no mercado, através da venda integrada, negociando assim, preços e condições com as indústrias.

Há que se considerar, no entanto, a necessidade de uma logística adequada para realizar essas ações, cujo ponto forte para os empreendimentos consiste no fato de que estão situados em áreas muito próximas uns dos outros, tornando mais viável tal ação.

Vale ressaltar que a criação e manutenção da rede indicam avanços consideráveis dos grupos no âmbito organizacional e de mobilização, fatores necessários para realização de reivindicações e que os legitime.

Muitos grupos, organizados em rede ou não, adquiriram notoriedade considerável e despertaram a atenção do poder público local, que vem há alguns meses conversando com os empreendimentos visando cumprir com o seu papel para a implementação da coleta seletiva nos municípios, e a devida inserção das cooperativas, conforme indicado na PNRS, através de sua contratação, e também previstos em estudos da ABRELPE (2014). Como exemplo, citam-se os municípios de Itaguaí, Mangaratiba e Japeri, cujos galpões para realizarem as atividades foram cedidos pelas prefeituras.

Outro resultado consiste no documento intitulado Plano de Negócios, importante ferramenta para o planejamento estratégico dos grupos. Fruto de uma construção coletiva entre a ITCP e os cooperados durante as atividades de assistência técnica, este documento poderá auxiliar no estabelecimento de uma parceria entre a cooperativa e a Prefeitura, por exemplo. Através da descrição do negócio da cooperativa, onde ela está e onde pretende chegar, com suas metas, projeções e demais itens específicos, há a possibilidade de um melhor conhecimento do empreendimento, bem como maior facilidade para as intervenções e identificação das necessidades da cooperativa. 
Do ponto de vista da ação do poder público, verifica-se a existência de questões a serem melhoradas e algumas oportunidades e caminhos para a inserção social dessas cooperativas, contemplando assim, parte dos catadores de materiais recicláveis. Há ainda um caminho com desafios consideráveis a serem preenchidos, e impactos de lacunas temporais a serem minimizadas.

Outra ação que poderia garantir o aumento de renda das cooperativas e aumentar as chances de sustentabilidade, consiste na inserção desses empreendimentos na logística reversa, numa espécie de parcerias com empresas que são obrigadas a implementá-la. Através da separação dos materiais da indústria em seus diversos seguimentos, a cooperativa poderia aumentar sua renda, e a indústria, por sua vez, ao comprar recicláveis, se beneficiaria com a economia de energia elétrica e matéria-prima virgem, além da mão de obra para triagem.

\section{CONCLUSÃO}

A Política Nacional de Resíduos Sólidos surge em um contexto que visa equacionar o problema da geração dos resíduos e sua correta destinação e disposição final, e imputa responsabilidades específicas e próprias para cada ator dentro do ciclo de vida dos produtos. Para que tenha efetividade, deve-se reforçar a inserção de uma mudança comportamental no cenário brasileiro.

A PNRS traz a obrigatoriedade da implementação da coleta seletiva nos municípios e da logística reversa, assim como a desativação das disposições finais inadequadas, os lixões ou aterros controlados, para implementação de uma disposição final ambientalmente adequada.

Devido à insuficiência de ações que pudessem respaldá-los, e apontando a existência de instituições que atuam com vistas a fortalecer a profissionalização dos catadores, o presente estudo descreveu o trabalho de uma delas, a ITCP COPPE UFRJ. Sua entrada e atuação ocorreram devido à necessidade dos grupos de apreenderem técnicas e ferramentas de organização e sustentabilidade. Através do 


\section{Revista Nacional de}

Gerenciamento de Cidades

projeto intitulado "Economia Solidária E Redes De Cooperação: Estratégias Para Inclusão Produtiva E Consolidação Da Sustentabilidade Dos Empreendimentos De Catadores", foi possível oferecer aos grupos capacitação e assistência técnica.

A atuação da ITCP visa fortalecer empreendimentos econômicos solidários ainda não inseridos de forma concreta na cadeia de reciclagem, com vistas a retirar - maior número possível de pessoas da condição de extrema pobreza. A estruturação e planejamento deste projeto visa alcançar a criação de um campo de proteção ambiental e social: quanto mais catadores bem qualificados e conscientes de suas tarefas são formados, mais resultado positivo terá em prol da preservação ambiental.

Entretanto, parte vital da inclusão desses grupos é também responsabilidade do poder público, através do cumprimento das disposições estabelecidas na PNRS, e com diminuição da lacuna temporal existente. É de fato, um desafio. O fortalecimento de empreendimentos formados por catadores através de apoio à infraestrutura do serviço torna-se uma alternativa para a otimização da coleta seletiva, contribuindo assim, para o aumento da escala de reciclagem de resíduos, visando à efetividade dos dispositivos estabelecidos na política pública ambiental.

\section{REFERÊNCIAS BIBLIOGRÁFICAS}

ASSOCIAÇÃO BRASILEIRA DE EMPRESAS DE LIMPEZA PÚBLICA E DE RESÍDUOS ESPECIAIS. ABRELPE. Resíduos Sólidos: Manual de Boas Práticas no Planejamento. Disponível em: <http://www.ambiente.sp.gov.br/cpla/files/2013/03/Manual-Boas-Praticas.pdf. > Acessado em 15 de Junho de 2015.

AMARAL, Elisa Buba. Principais diferenças entre Lixão, Aterro Controlado e Aterro Sanitário. Disponível em> < http://www.verdeghaia.com.br/blog/principais-diferencas-entre-lixao-aterrocontrolado-e-aterro-sanitario/> Acesso em 07 de maio de 2015.

BRASIL. Lei no 12.305, de 2 de agosto de 2010. Institui a Política Nacional de Resíduos Sólidos; altera a Lei $n^{\circ} 9.605$, de 12 de fevereiro de 1998; e dá outras providências. Publicado no Diário Oficial da União em 3.8.2010.

BRASIL. Plano Nacional de Resíduos Sólidos (versão preliminar). Ministério do Meio Ambiente: Brasília, $2012 . \quad$ Disponível em: 
